\title{
Relações entre pesquisa e clínica em estudos em cogestão com usuários de saúde mental
}

\author{
Relations between research and clinical care \\ in co-management studies with mental health care users
}

\author{
Analice de Lima Palombini ${ }^{1}$ \\ Rosana Teresa Onocko-Campos ${ }^{2}$ \\ Marília Silveira ${ }^{1}$ \\ Laura Lamas Martins Gonçalves ${ }^{2}$ \\ Lívia Zanchet ${ }^{1}$ \\ Maria Angélica Zamora Xavier ${ }^{1}$ \\ Cecília de Castro e Marques ${ }^{1}$
}

${ }^{1}$ Instituto de Psicologia, Universidade Federal do Rio Grande do Sul. Av.

Ramiro Barcelos 2600/136,

São Manoel. 90.035-003

Porto Alegre RS.

analicepalombini@uol.com.br

${ }^{2}$ Departamento de Saúde

Coletiva, Faculdade de

Ciências Médicas,

Universidade Estadual de

Campinas.

\begin{abstract}
This paper is derived from the experience of conducting research with mental health users (not about them, nor for them), analyzing aspects of a study in which different ways of structuring the relationship between clinical practice and research were put into play, thereby questioning the boundaries and ethical issues involved. The clinical practice and research fields that are dealt with are studied with the input of authors who, on the basis of institutional analysis, propose the idea of interventional research, and in the context of public health, revert to the concept of broadened clinical care. The relationship between these two terms - interventional research and broadened clinical care - is based on the notion of subjectivity that operates within the scope of public health and which culminates in the concept of autonomy. Lastly, co-management is proposed as a strategy based on which the different actors involved in conducting research and exercising clinical care can collectively build working principles that are both therapeutic and ethical. Key words Interventional research, Broadened clinical care, Co-management, Mental health
\end{abstract}

Resumo O artigo parte da experiência de pesquisar com usuários de saúde mental (e não sobre eles, ou para eles), narrando cenas de um estudo no qual se colocaram em jogo modos distintos de articulação entre pesquisa e clínica, problematizando suas fronteiras e as questões éticas implicadas. Situa o campo da clínica e da pesquisa de que se trata com o aporte de autores que, desde a análise institucional, propõem a ideia de pesquisaintervenção; e, no contexto da saúde coletiva, resgatam o conceito de clínica ampliada. Fundamenta-se a articulação entre esses dois termos - pesquisa-intervenção e clínica ampliada - desde a noção de subjetividade que opera no âmbito da saúde coletiva e que culmina na ideia de autonomia. Finalmente, propõe-se a cogestão como estratégia a partir da qual os diferentes atores implicados na condução da pesquisa e no exercício da clínica constroem coletivamente uma direção de trabalho, ao mesmo tempo terapêutica e ética. Palavras-chave Pesquisa intervenção, Clínica ampliada, Cogestão, Saúde mental 


\section{Introdução}

$\mathrm{O}$ artigo aborda a articulação entre pesquisa e clínica no campo da saúde mental, com base no estudo multicêntrico ${ }^{1}$ proposto a partir da experiência canadense de construção do Guia GAM: Gestion Autonome de la médication de l'âme Mon Guide Personnel ${ }^{2}$. Instrumento voltado a pessoas com transtornos mentais graves, o Guia traz informações e propõe perguntas para ajudar os usuários a inteirar-se de seu tratamento e a refletir sobre suas experiências cotidianas, seu adoecimento e sua medicação, incentivando sua participação ativa nas decisões que dizem respeito ao seu tratamento medicamentoso.

Entendendo que tal instrumento possibilitaria o enfrentamento do uso pouco crítico de medicamentos também no Brasil ${ }^{3}$, objetivou-se a elaboração do Guia Brasileiro da Gestão Autônoma da Medicação (Guia GAM-BR), com base na tradução, adaptação e aplicação crítica do Guia em serviços da rede pública de saúde. Proposta da Universidade em parceria com o movimento de usuários e os serviços públicos de saúde mental, a experiência de pesquisa com o Guia GAM no contexto brasileiro buscou fomentar a perspectiva dialógica, intersubjetiva, das relações entre usuários e pesquisadores, entre equipes dos serviços e usuários, entre pesquisadores e equipes.

$\mathrm{Na}$ sua primeira etapa, foram realizados grupos de intervenção (GI) em Centros de Atenção Psicossocial (Caps) em Campinas (SP), Rio de Janeiro (RJ) e Novo Hamburgo (RS), com a participação de usuários e trabalhadores. A participação dos serviços na pesquisa foi acordada em reuniões junto à gestão de saúde mental dos municípios e às equipes dos serviços. Posteriormente, os usuários foram informados do projeto em reuniões ou assembleias gerais nos serviços participantes. Fizeram parte dos GI os usuários interessados no tema ou indicados pela equipe e que faziam uso de psicofármacos há pelo menos um ano (em média oito usuários em cada GI). Dois ou três pesquisadores fizeram-se responsáveis pela condução de cada grupo. Estes pesquisadores não possuíam vínculo terapêutico prévio com os usuários que compuseram os GI, mas tinham formação clínica e experiência de trabalho em saúde mental que lhes permitiam o manejo clínico necessário para o desenrolar dos grupos. Além disso, a participação de um membro da equipe do serviço em cada GI, ao mesmo tempo em que configurava uma estratégia para capilarizar a experiência GAM ao serviço como um todo, também favorecia a sustentação da di- mensão clínica presente no processo grupal naquele contexto.

Ainda, estabeleceu-se uma instância analítica imediata a cada GI, na qual o grupo de condução deliberava sobre o acontecido naquele encontro e fazia registros em seus diários de campo. Realizaram-se também, periodicamente, encontros dos pesquisadores com a coordenação da pesquisa em cada campo, para análise da dinâmica dos GI. Nestes encontros, eram apontadas questões de manejo clínico, traçavam-se estratégias de articulação com as equipes dos serviços e zelava-se pela qualidade do material de campo que estava sendo construído.

Os GI desenvolveram-se ao longo de cerca de 20 encontros semanais, com duração média de 90 minutos. A leitura do Guia era o disparador dos encontros, a partir da qual emergiam diferentes temas em torno das experiências do cotidiano de vida dos participantes, não se restringindo aos tópicos propostos pelo Guia. Também eram colhidas as impressões e sugestões quanto ao seu texto e temário. A construção da versão final do Guia GAM-BR realizou-se a partir das modificações propostas pelos GI, debatidas em reuniões multicêntricas mensais, após o término dos GI, com a presença de pesquisadores, trabalhadores e usuários dos três campos. Numa segunda etapa, visando ao seu aprimoramento, a versão do Guia GAM-BR assim construída foi utilizada em novos GI junto a serviços de saúde nos municípios de Novo Hamburgo, São Leopoldo e Porto Alegre (RS), em São Pedro da Aldeia (RJ) e em Campinas (SP), em diferentes arranjos de coordenação, que ou incluíam diretamente a equipe de pesquisa; ou residentes e aperfeiçoandos com supervisão da equipe de pesquisa; ou, ainda, em um dos campos, sob a coordenação de dois usuários participantes da primeira etapa da pesquisa, que manifestaram seu interesse em transmitir a outros sua experiência, contando, para isso, com o apoio dos acadêmicos. O número de usuários participantes e o tempo de duração de cada GI foram semelhantes aos da primeira etapa. A revisão final do Guia, nessa segunda etapa, foi feita em um único encontro multicêntrico, após a sistematização, por cada campo, das sugestões e observações colhidas junto aos GI.

A experiência de pesquisar com usuários de saúde mental (e não sobre eles, ou para eles) evidenciou a necessária articulação entre pesquisa e clínica, que se colocava em jogo, neste estudo, de distintos modos. Com efeito, a articulação entre os saberes dos usuários, dos pesquisadores e das 
equipes dos serviços configurou um processo de gestão compartilhada ${ }^{4}$, impulsionando pesquisadores, trabalhadores e usuários a um esforço comum de formulação de estratégias que diziam respeito tanto ao curso da pesquisa como à direção do projeto terapêutico dos usuários e à gestão do trabalho no serviço de saúde. Pesquisa e clínica, portanto, ainda que distintas, não se experimentaram como disjuntas.

Eis algumas das situações vividas neste processo que colocam em cena modos de articulação entre a pesquisa que se conduzia e a clínica operada pelo serviço de saúde:

1. A constituição dos GI em cada um dos campos deu-se, como dissemos, com base no interesse manifesto dos usuários em debater o tema da medicação e ampliar seu poder de negociação quanto ao seu tratamento; mas também atendeu a indicações (terapêuticas) da equipe do serviço. Para alguns usuários, o Grupo GAM configurou uma via possível de engajamento em um trabalho grupal, quando outras ofertas de dispositivos grupais no serviço eram por eles recusadas. A pesquisa, nesses casos, abria caminho para a clínica.

2. Os encontros do GI proporcionaram, via de regra, uma aproximação inédita com a singularidade da história de vida de cada um dos usuários participantes, o que veio a repercutir no seu acompanhamento pela equipe do serviço: "Presta atenção, essa é a minha história, cuida bem disso que estou te contando" - era o que os olhares trocados, a cada relato, pareciam dizer, produzindo uma intensificação do vínculo dos usuários entre si e entre estes e os trabalhadores do serviço que acompanhavam o grupo. A cada novo encontro, os participantes mostravam-se menos receosos dessa aproximação, mais interessados em falar sobre o uso ou não de determinado medicamento prescrito e os efeitos produzidos no seu dia-a-dia. A assunção de uma voz própria e a intensificação das relações no grupo desdobravam-se em transformações na relação dos usuários com o serviço, que repercutiam em seus projetos terapêuticos. Víamos, então, a pesquisa mobilizando, intensificando a clínica.

3. Em um dos campos, o trabalho com a GAM levou ao engajamento forte de uma usuária no cotidiano do serviço, mobilizando outros usuários e trabalhadores para disparar processos compartilhados de gestão, produzindo mudanças na dinâmica do serviço e abrindo canais de comunicação e negociação com o gestor público - engajamento que se fez forte também na participação desta usuária no grupo de pesquisa. Voltados à gestão do serviço e à da pesquisa, os movimentos da usuária incidiam igualmente sobre seu processo subjetivo e eram incorporados como elementos do seu tratamento, referidos ao âmbito da clínica, à gestão do seu projeto terapêutico. A outro usuário, participante da pesquisa GAM e assíduo nas reuniões multicêntricas, os pesquisadores, ao testemunharem o momento crítico de vida por que passava, buscaram incentivá-lo a intensificar sua participação nos processos do estudo, ao lado daquela já mencionada. Este incentivo, dando-se no âmbito da pesquisa, estava concernido também à dimensão clínica do cuidado, de forma a mantê-lo ligado a um grupo, uma tarefa, um campo de significações - o dos medicamentos - pelo qual ele possuía especial interesse; ao mesmo tempo, a equipe do serviço foi alertada, no sentido de responder à demanda de cuidado que lhe estava colocada. Aqui, pesquisa e clínica caminhavam juntas, articulando-se pela via de uma construção coletiva, no compartilhamento da gestão de seus processos.

4. Em outro campo, foi-nos colocado como condição, para a realização do GI no serviço, que a equipe local (gestor e trabalhadores) pudesse tomar contato prévio com o conteúdo do guia e opinar a respeito. Tal engajamento resultou em assinalamentos que puderam ser levados em conta, em conjunto com as sugestões colhidas nos GI, na formulação da versão final do guia. Porém, levou também a impasses importantes na relação entre o grupo de pesquisa e a equipe do serviço, quando o que estava em jogo era o exercício de autonomia dos usuários. Assim, em especial com usuários que facilmente deixavam de aderir ao tratamento medicamentoso, a equipe considerou imprópria a leitura, no GI, da carta de direitos dos usuários, já que esta falava no de recusa ao tratamento. A bem da clínica, não recomendavam a carta, enquanto, para os pesquisadores, a terapêutica não poderia se sobrepor ao campo dos direitos. Aqui, clínica e pesquisa entravam em tensão, a partir de uma diferença de posição quanto ao estatuto da primeira na relação com o campo jurídico-político dos direitos, levando a um confronto que requeria negociação para poder alcançar uma gestão compartilhada.

Com base nessas situações, buscamos, neste artigo, apresentar e analisar as delicadas relações entre clínica e pesquisa no campo dos estudos com caráter de intervenção junto aos serviços de saúde mental, em parceria com seus trabalhadores e com ativa participação de seus usuários. Pretendemos, assim, contribuir com o manejo desse tipo de situações, apontando alguns cuida- 
dos imprescindíveis - éticos, clínicos e científicos - que tais investigações impõem ao pesquisador. Considerando a brevidade do artigo, centramonos na articulação entre pesquisa e clínica que se engendra especialmente na relação entre pesquisadores e usuários, mais do que na relação protagonizada pelos trabalhadores em contato com a pesquisa. Como disparador de nossas reflexões, apresentamos narrativas colhidas de diferentes produções textuais que acompanharam a realização da pesquisa: diários de campo; memórias dos grupos de intervenção, dissertações de mestrado. Tais narrativas foram escolhidas por sua força expressiva e pela capacidade de condensar as problematizações de que nos ocupamos, como imagens do pensamento, tal como propõem os estudos literários 5 .

\section{Que pesquisa e que clínica autorizam essa articulação?}

Num dos últimos encontros [do GI], quando lemos a pergunta 'Quem poderia nos ajudar a enfrentar estas dificuldades?', Davi respondeu que estava sozinho, que tinha vontade de falar com alguém, mas não sabia com quem. Sentia que seria bom ter uma terapeuta. O grupo todo se movimentou na direção de se oferecer a ele como apoio e também indicou os espaços terapêuticos do serviço, os dias dos grupos de terapia e quem eram os profissionais de referência. Ao que ele agradeceu, contando que 'um tempo atrás' desconfiava do remédio que o psiquiatra receitava e, então, não tomava. Mas que a conversa no Grupo GAM havia ajudado a acreditar no médico, no remédio, no tratamento. E o efeito disso era que ele se sentia sozinho. Ele não nos disse, mas víamos o Davi conversando com as vozes que só ele escutava, uma conversa amena sempre, que parecia oferecer algum conforto. Ao mesmo tempo em que ele, desconfortável perante o grupo, colocava o Guia aberto na frente da boca, talvez para esconder a conversa com as vozes. Nos encontros que antecederam esse, não o víamos mais colocando o Guia em frente à boca. Talvez as vozes não estivessem mais com ele. Talvez o medicamento tivesse calado as vozes. Entretanto, era justamente nesse momento que a clareza de sua solidão evidenciava-se para si mesmo. (narrativa de campo na voz do pesquisador - GI $2^{\text {a }}$ etapa, sob coordenação dos usuários $)^{6}$

\section{Subjetividade}

Uma das dimensões que passam a ser contempladas, desde a década de 1990, no campo da saúde coletiva é a da subjetividade, especialmente implicada em relação à saúde mental, cujas práticas requerem a voz ativa de seus usuários. Conforme afirmam Onocko Campos e Campos ${ }^{7}$, "esta valorização do 'sujeito' e de sua singularidade - da qual o relato acima dá mostras - altera radicalmente o campo de conhecimento e de práticas da saúde", incidindo sobre a articulação pesquisa-clínica que propomos abordar. A noção de subjetividade, contudo, adquire sentidos diversos, relacionados à função que vem ocupar em distintos momentos da história das políticas de saúde no Brasil. É o que estabelece o texto de Ferreira Neto et al. ${ }^{8}$, ao discorrer sobre os usos dessa noção no campo da saúde coletiva, associando-os à trajetória do movimento sanitário e à institucionalização do Sistema Único de Saúde (SUS), no entrecruzamento entre um plano micropolítico - relativo às singularidades a se levar em conta em cada situação, envolvendo "a produção intensiva de percepções, afetos, conversas" - e um plano macropolítico - concernente ao sujeito coletivo que incide sobre a constituição do aparato jurídico-institucional das políticas públicas. $\mathrm{O}$ autor distingue três funções que a ideia de subjetividade operaria no campo das políticas de saúde.

A primeira função, relativa à trajetória do movimento sanitário na construção do SUS, permite contrapor, ao determinismo estrutural - que marcava majoritariamente a visão marxista desse movimento -, o protagonismo de seus atores como agentes de mudança, remetendo, assim, a uma valorização da ação social de sujeitos políticos engajados no processo coletivo da reforma sanitária ${ }^{8}$.

A segunda função reporta-se à necessidade de transformação das práticas, na medida em que a institucionalização do SUS não se mostra suficiente para gerar mudanças nos modos de produção de saúde. Enfatizando a dimensão relacional da subjetividade, seu caráter intersubjetivo, trata-se de ressaltar a perspectiva dialógica imanente às práticas de saúde - o que incide tanto nas ações de cuidado como nas de gestão, evidenciando um vínculo indissociável entre cuidado e gestão.

Finalmente, a terceira função remete à produção de autonomia dos indivíduos e coletivos envolvidos nas ações de saúde. Também designada como participação, protagonismo, empoderamento ${ }^{9,10}$, termina por ocupar um lugar paradoxal, que a torna sujeita às críticas ao remeter a uma perspectiva neoliberal e individualista de subjetividade. $\mathrm{O}$ enfrentamento desse paradoxo exi- 
ge tomar o conceito de autonomia em sua complexidade - como afirma Kinoshita ${ }^{11}$ no tocante ao movimento da reforma psiquiátrica brasileira: quanto mais vínculos e maior rede de relações as pessoas estabelecem, maior sua autonomia.

O uso da noção de subjetividade no campo das políticas de saúde no Brasil reitera o caráter eminentemente político da proposta do SUS. O político, ao incorporar a dimensão da subjetividade - sem confundi-la com a ideia de interioridade psicológica -, desloca "o foco sociológico de fundo marxista para um diálogo mais ampliado com o campo das ciências humanas" ${ }^{\text {, em }}$ especial com a filosofia e com a psicanálise, ampliando o diálogo interdisciplinar no campo da saúde coletiva.

\section{Clínica ampliada}

No tocante à clínica - entendida como o conjunto de práticas profissionais (não somente médicas), voltadas ao diagnóstico, tratamento, reabilitação e prevenção secundária no campo da saúde ${ }^{12}-$, a necessidade de incorporar às suas práticas certa capacidade de lidar com a subjetividade não é novidade ${ }^{13}$ - ainda que a sua realização siga sendo um desafio. É no conceito psicanalítico de transferência que Cunha ${ }^{13}$ busca aporte para um reposicionamento da clínica que, tradicionalmente realizada de forma independente do sujeito (ou apesar dele), passa a requerer sua participação ativa, de modo que a resistência mesma que o sujeito possa aí manifestar é o que move o seu tratamento.

A Saúde Coletiva, porém, tendeu de início a afirmar o seu âmbito de atuação em oposição ao da clínica, contrapondo as práticas coletivas de prevenção e promoção da saúde à esta como prática individual. No entanto, nem a eficácia da Saúde Coletiva pode prescindir daqueles que tratam, nem a clínica tem seu modo de operar e seu alcance reduzidos ao individual ${ }^{12}$.

A clínica a que nos reportamos aqui é, portanto, a ampliada. Campos ${ }^{14}$ situa o mote dessa ampliação: é em sujeitos encarnados que os problemas de saúde ou a doença acontecem, logo, para além dos riscos biológicos, deveriam ser considerados os subjetivos e sociais de cada usuário, buscando superar a estreiteza do paradigma biomédico. Além da produção de saúde, tratar-se-á de favorecer também a ampliação do grau de autonomia dos usuários ${ }^{14}$. A clínica, então, se faz especialmente pela via da escuta e da palavra, da educação em saúde e do apoio psicossocial, implicando a construção de vínculo e a corresponsabilização do clínico e do usuário ao longo do processo ${ }^{14}$.

Tal ampliação não recusa os recursos da biomedicina, mas os desloca do lugar absoluto a que foram alçados, colocando-os em relação com outras disciplinas e saberes, abertas ao saber singular dos sujeitos. Os saberes biomédicos “constituem-se 'mais uma força' entre tantas outras na Vida do Sujeito"13. Afirma-se o saber e o papel ativo do usuário em defesa de sua saúde, interligada à de outros, reconhecendo os limites de qualquer saber estruturado diante das situações concretas e complexas da vida, aceitando o desafio de "passar deste campo de certezas, de regularidades mais ou menos seguras, ao campo da imprevisibilidade radical da vida cotidiana" ${ }^{\text {. }}$ Reconhecer os limites dos saberes que estão em jogo compreende desenvolver certa capacidade crítica em relação a eles, identificando os poderes que lhes são associados ${ }^{4,13}$. O exercício da clínica, portanto, não se separa do político, do ético, do estético $^{15}$.

\section{Pesquisa-intervenção}

A valorização e o aumento do grau de autonomia dos sujeitos através do fomento à participação coletiva e à corresponsabilidade nas práticas de saúde requerem, para seu estudo, pesquisas ampliadas, onde autonomia, participação coletiva e corresponsabilidade sejam igualmente o mote: uma pesquisa feita com os sujeitos e não sobre eles ${ }^{16}$.

Assim, o desafio de realizar a pesquisa com os usuários se cumpre a partir de uma postura ética de resistência às formas de assujeitamento no campo da pesquisa. O pesquisador evita assumir uma posição de julgamento desde um conjunto de regras coercitivas que definem a priori o que é certo ou errado, tampouco encena uma pretensa neutralidade. As pessoas são convidadas a estarem lado a lado, desde as suas diferenças, compartilhando experiências - pois autonomia e protagonismo se constroem justamente nas relações de alteridade. Lado a lado, rompem-se as barreiras entre sujeito que conhece e objeto a ser conhecido: sujeito e objeto, pesquisador e campo de pesquisa, criam-se ao mesmo tempo ${ }^{17}$.

Rompem-se também as barreiras que separam a clínica da pesquisa. Freud ${ }^{18,19}$, a seu tempo, já afirmara a indissociabilidade entre a experiência analítica e a produção de seu saber - saber sempre inconcluso, aberto às vicissitudes dos caminhos que a experiência leva a percorrer. Clínica e pesquisa, nessa perspectiva, configuram 
um mesmo plano de ação, no qual se trata de acessar, promover, acompanhar um movimento - o que requer um saber-fazer que se faz no próprio movimento, sem a definição prévia de uma meta a ser alcançada ${ }^{20,21}$.

A Análise Institucional Socioanalítica confere-lhe o caráter de pesquisa-intervenção, onde intervenção não significa o restabelecimento de uma ordem, mas visa interrogar os diversos sentidos cristalizados nas instituições, produzindo evidências que revelem o jogo de interesses e de poder emanados do campo de investigação ${ }^{17}$. À produção dessas evidências, que fazem com que a experiência de análise não deixe de fora sua própria instituição ${ }^{22}$, os socioanalistas denominam de "análise de implicação": a aproximação com o campo requer a permanente análise do impacto que as cenas vividas/observadas têm sobre a história do pesquisador e sobre o sistema de poder, incluindo aí o próprio lugar de saber e estatuto de poder do pesquisador ${ }^{23}$.

\section{Pesquisa e clínica em cogestão da experiência GAM}

Em um encontro do GI, a condução do grupo viu-se dificultada em função de um dos participantes se encontrar, naquele dia, particularmente ansioso: falava muito e monopolizava a palavra, apesar das intervenções dos condutores e dos demais usuários. Várias vezes emocionou-se, ao lembrar de situações difíceis na sua vida, evocadas pelas temáticas discutidas, e sobre elas discorreu sem dar chance para que outros interagissem. Após o término desse encontro, nós, coordenadores, debatemos nossa dificuldade de condução: como garantir a circulação da palavra e acolher um usuário em momento de maior fragilidade e desorganização? Indagamo-nos se, numa situação como esta, seria nossa função entrar em contato com o serviço de referência para conversar sobre nossa percepção quanto à 'piora clinica' de um integrante da pesquisa e sustentamos esse ponto como uma questão. Percebemos que poderíamos ter conversado com o usuário ao final do grupo, oferecendo-lhe uma maior acolhida, até para podermos ajudar nas articulações que se fizessem necessárias. Retornava aqui a questão sobre qual nossa função, como pesquisadores condutores de um grupo que convida ao compartilhamento de experiências: cuidamos 'instigando' ou instigamos cuidando? Nossa função seria promover autonomia e capacidade crítica frente ao serviço e, ao mesmo tempo, promover um maior vínculo com o próprio serviço. Como manejar isso no grupo? Ao potencializarmos a relação com o serviço como es- paço de cuidado corresponsável a partir da experimentação no grupo, estaríamos constituindo o GI como espaço de cuidado? Se sim, qual o risco de que viéssemos a 'competir' com o cuidado produzido no serviço de referência? Quando fortalecemos a capacidade crítica do usuário perante o serviço, corremos o risco de enfraquecer o vínculo que os une [tênue limite entre o que potencializa e enfraquece]? (narrativa de campo na voz dos pesquisadores - GI $1^{\text {a }}$ etapa).

O trabalho de pesquisa foi orientado pelo entendimento de que a decisão quanto ao melhor tratamento se faz em uma composição entre os saberes do usuário e da equipe de referência, em uma gestão compartilhada do cuidado que engendre processos de autonomia ${ }^{4,24}$, diferentemente daqueles de autogestão em que usuários ou profissionais da equipe tomariam as decisões sem compartilhamento. Tal exercício de autonomia, porém, implicava no deslocamento dos lugares já estabelecidos, afetando o quotidiano dos serviços e o processo da pesquisa, abrindo interrogantes aos nossos fazeres.

[Num dos encontros do GI, um dos usuários participantes] perguntou: 'Mas o que vocês querem, afinal? Querem que a gente questione os médicos? Que a gente faça perguntas a eles sobre nossa medicação?' O tom da pergunta foi quase de indignação e assim revelou o que poderia estar se atualizando na relação pesquisadores-usuários como a nossa 'prescrição'. Retomamos o objetivo do grupo e a importância de construirmos os sentidos de conversarem ou não com os médicos para negociação da medicação e de como fazer essa conversa. Alguns então disseram que não viam mesmo por que falar com seus médicos naquele momento. Nosso receio frente a essa situação foi o de que nosso 'querer' que compartilhassem mais sobre seus medicamentos e sobre o significado dos mesmos em suas vidas com os médicos entrasse no mesmo lugar prescritivo que o remédio (narrativa de campo na voz dos pesquisadores - GI $1^{\text {a }}$ etapa $)^{25}$

Esse exercício não foi fácil, e se fez - em muitos casos - em um passo a passo que requereu inúmeras leituras clínicas. Quando era importante respeitar e esperar a iniciativa própria de um usuário, seu tempo e maneira de lidar com seu serviço? Quando uma precipitação da equipe de pesquisa advertindo a equipe do serviço poderia vir a abortar um movimento do sujeito? Ou, pelo contrário, quando a situação requeria a prontidão para uma intervenção imediata, em que a comunicação à equipe de referência não poderia se fazer esperar? Caso a caso, simultaneamente à condução dos grupos como dispositi- 
vos de construção de dados para a investigação, fomos convocados a tomar decisões que diziam respeito à dimensão clínica e ao cuidado de muitos dos participantes.

Alguns encontros depois, [esse mesmo usuário] compartilhou com o grupo que tinha ido falar com o seu médico a respeito de seus remédios e disse que, a partir desta conversa, um dos medicamentos fora retirado. Perguntamos a ele o que o tinha motivado a falar com o médico, e outros usuários questionaram por que o médico tinha tirado um dos remédios, e ele não sabia responder. Apenas dizia que o médico tinha tirado um remédio e que ele tinha achado bom e que o médico tinha dito para ele não se preocupar... (narrativa de campo na voz dos pesquisadores - GI $1^{\text {a }}$ etapa $)^{25}$

Nessa vinheta podemos ver como o avanço obtido foi gradual. A não antecipação da equipe de pesquisa - a espera que, com Oury ${ }^{26}$, poderíamos chamar de ativa - foi permitindo graus de compreensão maior dos participantes. A nós próprios, pesquisadores, suportar essa espera permitiu-nos aprofundar o entendimento da complexidade dessa mudança de relações entre usuários e prescritores, para a qual a informação era somente o passo inicial, mas de nenhuma maneira o único nem o mais importante. Os usuários pareciam precisar de um tempo para acreditar na própria experiência como fonte de outro tipo de conhecimento, o qual também caberia incorporar às práticas clínicas.

Ficamos sem saber o quanto nossas intervenções no grupo haviam despertado uma vontade de rever suas medicações, o quanto haviam produzido uma nova 'submissão' ao desejo/'mando' de outra autoridade [a dos pesquisadores]. O grupo apontou certo 'sem sentido' nesse pedido [do usuário], 'sem sentido' que se confirmou na não produção de mudança na experiência dele com o médico e também com o remédio. Ele, que denunciara em encontro anterior um movimento prescritivo de nossa parte, acabou de certa forma sucumbindo a essa prescrição e fazendo um movimento em que prevaleceu uma sensação de 'sem sentido'. (narrativa de campo na voz dos pesquisadores GI $1^{\text {a }}$ etapa $)^{25}$

A aposta na gestão compartilhada do tratamento rompe com a lógica dicotômica que opõe clínica/política, indivíduo/sociedade, dentro/fora, público/privado, e que refere o sujeito a um espaço privado, a uma experiência privatizante. Com essa proposta, demarcamos, então, um jeito de fazer pesquisa e de produzir saúde, favorecendo a inclusão dos usuários nas decisões referentes aos rumos tanto da pesquisa quanto de seus tratamentos, de modo que os encontros entre pesquisadores, usuários e profissionais da saúde fossem tomados como espaços e momentos de debate e análise do próprio fazer em saúde, recompondo ou reorganizando conhecimentos, técnicas e instrumentos e construindo, assim, novos sentidos para o trabalho e o tratamento $^{27}$. Sob o pressuposto ético de que pesquisa e produção de saúde se fazem com o outro e não apesar dele, possibilitaram-se convivências e trocas entre pessoas por vezes até então prisioneiras do seu próprio adoecimento. Não se buscava aí produzir normalidade, mas vislumbrar outras perspectivas de vida - por exemplo, de usuário-diagnosticado a usuário-pesquisador.

[Outro usuário], com ativa participação política em sua cidade, chegou ao Caps onde se tratava e disse estar se organizando para uma viagem ao Canadá [fato realmente aventado no grupo de pesquisa]. Ele nos relata posteriormente que algumas pessoas do serviço acharam que ele estava delirando, e se perguntavam se na realidade ele não estaria piorando. À nossa proposta, então, dirigida ao grupo todo [os GI], de enviarmos uma carta a cada serviço explicando que eles estavam participando dos GI, eles recusaram. Propuseram em troca que a carta fosse elaborada, sim, mas entregue a eles mesmos, de forma que cada um ficaria à vontade para utilizá-la ou não. (narrativa de campo na voz dos pesquisadores - GI $1^{\text {a }}$ etapa)

Vivemos, assim, junto com os usuários, a expectativa desses desdobramentos, mantendonos atentos, mas contendo nossa ansiedade, críticos de nós mesmos para não anteciparmos ações que apenas poderiam ganhar relevância se desenvolvidas pelos próprios usuários.

$\mathrm{Na}$ segunda etapa da investigação, como foi dito acima, uma dupla de usuários que havia participado da anterior tomou a frente na condução de um GI, sendo acompanhada pelos pesquisadores. Durante a realização desse GI, aconteceu da usuária mais proativa da dupla adoecer e solicitar à pesquisadora que coordenasse o grupo por ela naquele dia. Por muito pouco a pesquisadora do campo e a trabalhadora do serviço que acompanhava o grupo não se precipitaram na sua condução, desconsiderando que havia outro usuário envolvido a quem cabia esta tarefa. Retomando os lugares de cada um, a pesquisadora solicitou que ele iniciasse o grupo:

Ele então pediu licença para as pessoas e retomou a tarefa da leitura [...], pediu à pesquisadora que iniciasse a leitura, pois 'não estou bem para ler hoje.' Começaram, assim, a leitura, e, a cada parada, ele fazia intervenções, escutava a todos, coor- 
denava quando a conversa avançava longe demais do tema, solicitava o retorno à leitura, perguntava quem queria seguir lendo, questionava as intervenções dos demais usuários e em alguns momentos também conversava com suas vozes, aquelas que ninguém mais ali podia ouvir. (narrativa de campo na voz do pesquisador - GI 2a etapa, sob coordenação dos usuários) ${ }^{6}$

A palavra "louco" ou um diagnóstico de transtorno mental grave costuma impregnar de tal forma a vida de um sujeito que torna impeditiva a sua existência. $\mathrm{O}$ diagnóstico pode ganhar tal visibilidade que torna invisível o sujeito. $\mathrm{Na}$ experiência do GI, aquele usuário mostrou-nos outro universo de referência: ele, que escutava vozes, pôde escutar as vozes das pessoas que falavam naquela sala. E por que não poderia?

O sintoma é um pássaro que bate com o bico na janela. A bela imagem que nos oferece Guattari sinaliza uma direção de trabalho: não se trata de interpretá-lo [o sintoma]. Trata-se antes de detectar sua trajetória para ver se pode servir de indicador de novos universos de referência suscetível de adquirir uma consistência suficiente para revirar uma situaçãa $0^{28}$. Ao retirar o diagnóstico do foco da cena, o que era sintoma a ser debelado ou decifrado podia transformar-se em potência da qual fazer uso - potência de ouvir, para além das vozes alucinadas, as vozes dos que se encontravam ao seu lado.

\section{O que pudemos aprender desta experiência?}

Do ponto de vista metodológico, nossa pesquisa permite colocar em questão alguns dos sinais de alerta dirigidos aos estudos qualitativos ${ }^{29}$. Se, com efeito, numa concepção tradicional da pesquisa qualitativa, a relação clínica prévia entre pesquisador e sujeitos de pesquisa constitui grave limitação do estudo, uma vez que pode influenciar a opinião dos entrevistados ou caracterizar um modo de constrangimento ou coerção; na pesquisa-intervenção com pessoas com transtornos graves de saúde mental, cabe outra consideração.

Dissemos acima que todos os pesquisadores envolvidos possuíam formação clínica e experiência de trabalho em saúde mental. $O$ fato de estarmos dessa forma "advertidos" - como diria Oury $^{26}$ - permitiu-nos cuidar de inúmeras situações de interface clínica. Ou seja, conhecíamos a clínica das psicoses, tínhamos experiência com o manejo de grupos no contexto da saúde mental, contávamos com essa expertise em nosso grupo de pesquisadores. Nunca nos despimos de nossa responsabilidade e compromisso ético com os cuidados dos usuários que conosco trabalharam. Mantivemo-nos atentos, o tempo todo, à delicada articulação do campo da investigação com o campo da clínica e da gestão dos equipamentos. Essa característica, longe de concorrer com os objetivos da investigação, contribuiu para obtermos um material qualitativo rico e denso.

As pesquisas-intervenção no campo da saúde se beneficiam muito quando são desenvolvidas por pessoas com familiaridade com esse campo, que não precisam de aculturação, e que estejam em condições, não apenas de manejo da pesquisa, mas também de um clínico, quando a intervenção de que se ocupam envolve a participação de usuários.

Em nossa experiência, constatamos que, a cada passo do processo, encontrávamo-nos relacionados à pesquisa, à gestão e à clínica com as suas zonas de fronteira, com seus limites de território, mas, também, com os seus litorais, essa zona em que os limites se tornam indiscerníveis, requerendo um trabalho comum, o compartilhamento e o acompanhamento mútuo das ações. Algo que foi se fazendo à medida que a pesquisa avançava.

Por vezes, essas relações entre pesquisa, gestão e clínica embaralhavam-se, criando situações inesperadas que precisaram ser manejadas de forma inventiva. Então, era preciso o esforço de todos para dar contorno a cada lugar, distribuir e discernir responsabilidades, reconhecer limitações, dar crédito ao outro, sustentar a possibilidade de parceria.

As trocas de saberes entre os diferentes atores que compuseram a cena da pesquisa, da gestão e da clínica permitiram, a cada um, experimentar uma mudança de lugar e um exercício de construção coletiva. Essa experiência pôde sustentarse pela aposta de que mudar de lugar muda o lugar ${ }^{27}$.

Assim, um usuário pode ser pesquisador ao explorar conceitos por meio do estudo de textos, mas também ao compartilhar sua própria experiência de adoecer e receber tratamento. Pesquisadores podem ser menos distantes e abstratos ao se aproximarem do mundo da vida, abrindo-se ao encontro com a experiência. A equipe pode ser mais pesquisadora, propondo-se ao exame crítico de suas práticas. $\mathrm{O}$ gestor pode se propor exercer a gestão de forma lateralizada, colocando-se ao lado de trabalhadores, usuários e pesquisadores.

O desafio de transformação das práticas é coletivo. Implica pesquisa e clínica num esforço 
de cogestão que tem, como ponto de base, o exercício da autonomia e do protagonismo dos usuários em todos esses âmbitos - na pesquisa, na gestão e na clínica. Tal exercício requer, por sua vez, o encontro com a autonomia e o protagonismo de gestores, trabalhadores e pesquisadores com quem os usuários se colocam em relação.

\section{Colaboradores}

AL Palombini, CC Marques, MAZ Xavier, L Zanchet, LLM Gonçalves, M Silveira e RT OnockoCampos participaram igualmente de todas as etapas de elaboração do artigo.

\section{Referências}

1. Onocko Campos R, Palombini AL, Silva AE, Passos E, Leal E, Serpa O, Marques CC, Gonçalves LL, Santos DVD, Surjus LT, Arantes RL, Emerich B, Otanari TMC, Stefanello S. Adaptação multicêntrica de um Guia para a Gestão Autônoma da medicação. Interface (Botucatu) 2012; 16(43):967-980.

2. RRASMQ-ÉRASME. Repères pour une Gestion autonome de la médication en santé mentale. Guide d'accompagnement. RRASMQ-ÉRASME: Montreal; 2006.

3. Onocko Campos R, Gama CA, Ferrer AL, dos Santos DVD, Stefanello S, Trape TL, Porto K. Mental health in primary care: An evaluative study in a large brazilian city. Cien Saude Colet 2011; 16(12):4643-4652.

4. Campos GWS. Um método para análise e cogestão de coletivos: a constituição do sujeito, a produção de valor de uso e a democracia em instituições: o método da roda. São Paulo: Hucitec; 2000.

5. Guerreiro A. A difícil arte de passear. Revista Semear 2002: 6. [página na Internet]. [acessado 2013 maio 11]. Disponível em: http://www.letras.puc-rio.br/ unidades\&nucleos/catedra/revista/6Sem_19.html

6. Silveira M. Vozes no corpo, territórios na mão: loucura, corpo e escrita no PesquisarCOM [dissertação]. Porto Alegre: Universidade Federal do Rio Grande do Sul; 2013.

7. Onocko Campos R, Campos GW. Co-construção de autonomia: o sujeito em questão. In: Campos GWS, Minayo MCS, Akerman M, Drumond Júnior M, Carvalho YM, organizadores. Tratado de saúde coletiva. São Paulo, Rio de Janeiro: Hucitet, Fiocruz; 2006.

8. Ferreira Neto JL, Kind L, Pereira AB, Rezende MCC, Fernandes ML. Usos da noção de subjetividade no campo da saúde coletiva. Cad Saude Publica 2011; 27(5):831-842.

9. Campos GWS. Sobre a peleja dos sujeitos da reforma ou da reforma dos sujeitos da peleja. Saúde Soc 1992; 1:79-95.

10. Brasil. Ministério da Saúde (MS). Política Nacional de Promoção de Saúde. Brasília: MS; 2006. 
11. Kinoshita RT. Contratualidade e reabilitação psicossocial. In: Pitta A, editor. Reabilitação psicossocial no Brasil. São Paulo: Hucitec; 1996. p.55-59.

12. Onocko Campos R. Clínica: a palavra negada sobre as práticas clínicas nos serviços de saúde mental. Saúde em Debate 2001; 25(58):98-111.

13. Cunha GT. A construção da clínica ampliada na atenção básica. São Paulo: Hucitec; 2005.

14. Campos GWS. A clínica do sujeito: por uma clínica reformulada e ampliada. Mimeo, 1996/1997. [página na Internet]. [acessado 2013 ago 10]. Disponível em: http://www.gastaowagner.com.br/index.php/ artigos/cat_view/6-artigos

15. Passos E, Benevides de Barros R. A construção do plano da clínica e o conceito de transdisciplinaridade. Psicologia: teoria e pesquisa 2000; 16(1):71-79.

16. Onocko Campos R. Fale com eles! O trabalho interpretativo e a produção de consenso na pesquisa qualitativa em saúde: inovações a partir de desenhos participativos. Physis 2011; 21(4):1269-1286.

17. Benevides de Barros R. Grupo: a afirmação de um simulacro. Porto Alegre: Sulina; 2007.

18. Freud S. Dois verbetes de enciclopédia. In: Freud S. Edição standard brasileira das obras psicológicas completas. Rio de Janeiro: Imago; 1976. Vol. XVIII. p. 283-312.

19. Freud S. Os instintos e suas vicissitudes. In: Freud S. Edição standard brasileira das obras psicológicas completas. Rio de Janeiro: Imago; 1976. Vol. XIV. p. 127-162.

20. Passos E. A clínica, o método e as experiências de passagem. Conferência de abertura do I Congresso Internacional de Acompanhamento Terapêutico. São Paulo, 7, 8 e 9 de setembro de 2006. Não publicado.

21. Palombini A. Vertigens de uma psicanálise a céu aberto: a cidade. Contribuições do acompanhamento terapêutico à clínica na reforma psiquiátrica [tese]. Rio de Janeiro: Universidade do Estado do Rio de Janeiro; 2007.
22. Lourau R. Implicação e Sobreimplicação. In: Altoé S, organizador. Analista Institucional em tempo integral. São Paulo: Hucitec; 2004. p. 186-198.

23. Paulon SM. A análise de implicação como ferramenta na Pesquisa-Intervenção. Psicologia e Sociedade 2005; 17(3):16-23.

24. Campos GWS, Onocko Campos R. Co-construção de autonomia: o sujeito em questão. In: Campos GWS, Minayo MCS, Akerman M, Drumond Júnior M, Carvalho YM, organizadores. Tratado de saúde coletiva. São Paulo, Rio de Janeiro: Hucitet, Fiocruz; 2006. p. 669-714.

25. Gonçalves LLM. A Gestão Autônoma da Medicação numa Experiência com Usuários Militantes da Saúde Mental [tese]. Campinas: Universidade Estadual de Campinas; 2013.

26. Oury J. Itinerários de formação. Revue Pratique 1991; 1:42-50.

27. Marques CC. Entre nós: sobre mudar de lugar e produzir diferenças [dissertação]. Porto Alegre: Universidade Federal do Rio Grande do Sul; 2012.

28. Deleuze G. Crítica e Clínica. São Paulo: Ed. 34; 1997.

29. Clark JP. How to peer review a qualitative manuscript. In: Godlee F, Jefferson T, editors. Peer Review in Health Sciences. $2^{\text {nd }}$ Edition. London: BMJ; 2003. p. 219-235.

Artigo apresentado em 22/03/2013

Aprovado em 27/04/2013

Versão final apresentada em 18/05/2013 